\title{
A mini-corer for precision sampling of the water-sediment interface in subglacial lakes and other remote aqueous environments
}

\author{
Peter Keen (1), ${ }^{1 *}$ Kevin Saw, ${ }^{2}$ Nicholas Rundle, ${ }^{2}$ Robin Brown, ${ }^{2}$ James Wyatt, ${ }^{2}$ Stephen Shorter, ${ }^{2}$ \\ Michael Edwards, ${ }^{3}$ Martin Siegert, ${ }^{4}$ Matthew Mowlem ${ }^{2}$ \\ ${ }^{1}$ Keen Marine Limited, East Cowes, United Kingdom \\ ${ }^{2}$ National Oceanography Centre, Southampton, United Kingdom \\ ${ }^{3}$ British Ocean Sediment Core Research Facility, Southampton, United Kingdom \\ ${ }^{4}$ Imperial College London, London, United Kingdom
}

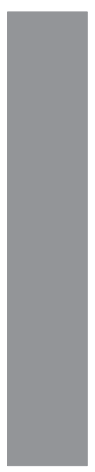

\begin{abstract}
Recent interest in Antarctic subglacial lakes has seen the development of bespoke systems for sampling them. These systems are considered pristine environments potentially harboring undisturbed sedimentary sequences and ecosystems adapted to these cold oligotrophic environments in the absence of sunlight. The water/sediment interface is considered a prime location for the detection of microbial life and so is of particular interest. This article describes the development of a small corer to capture and retain a short core that includes the water/sediment interface specifically to address the question of whether life exists in these lakes. This apparatus was developed as part of the UK led project to access, measure, and sample subglacial Lake Ellsworth. In addition to addressing the constraints of coring in this difficult environment, the results of subsequent testing suggest that this corer can be applied to sampling sediments in other environments and would be particularly useful in low energy environments when the water-sediment interface is indistinct or unconsolidated.
\end{abstract}

Lake Ellsworth is located at $78^{\circ} 58^{\prime} 34^{\prime \prime} \mathrm{S}, 090^{\circ} 31^{\prime} 04^{\prime \prime} \mathrm{W}$ in West Antarctica within the uppermost catchment of the Pine Island Glacier. It is located at the bottom of a deep, subglacial fjord-like trough approximately $3000-3250 \mathrm{~m}$ below the ice surface (Siegert et al. 2004; Vaughan et al. 2007). In the Austral summer of 2012, an expedition from the United Kingdom, led by a UK consortium (Seigert 2012), planned to create a borehole through the overlying ice cap and deploy sampling equipment into the lake waters and underlying sediment. The scientific aims were principally "(1) to detect and comprehend life in this extreme environment and (2) to collect and assess any climate records that exist in the lake floor sediments" (Siegert 2006). Lake access was not achieved in the 2012 field season (Siegert et al. 2014) but the scientific objectives remain relevant (as evidenced through the Scientific Committee on Antarctic Research 20-yr horizon scan exercise; Kennicutt 2014) and, as over 400 subglacial lakes are now known across a variety of settings (Siegert 2016), further experiments are anticipated (Siegert et al. 2015).

Seismic reflection studies indicate Lake Ellsworth has a maximum water depth of approximately $150 \mathrm{~m}$ and that the lakebed is

*Correspondence: pwk@keen-marine.com

This is an open access article under the terms of the Creative Commons Attribution License, which permits use, distribution and reproduction in any medium, provided the original work is properly cited. composed of high-porosity, low-density sediment with acoustic properties similar to material found on the deep-ocean floor. The sediment is estimated to be a minimum of $6 \mathrm{~m}$ deep (Smith 2008).

In ultra-oligotrophic lakes such as Lake Ellsworth, the watersediment interface is likely to be a prime site for the detection of microbial life (Seigert 2012). Therefore, sediment sampling is key to answering both scientific questions posed by the project.

This article describes the specification and development of a mini-corer to be mounted on the front of an instrumented sampling probe. This corer is specifically designed to capture a short sediment core and preserve, intact, the sediment-water interface. This will address the question of whether life exists in the lake. For this purpose, only a small sample that includes the watersediment interface is required. Deeper sediment sampling is also planned using a much larger percussion corer (Hodgson 2016), to collect sedimentary sequences for climatic analysis but was not designed to capture an undisturbed water-sediment interface.

\section{Design considerations}

Substrate and sample composition

The Lake access and sampling site has been specifically chosen to target the deepest and least disturbed location within the lake where it is more likely that the sediment sequence will be intact (Woodward 2010). As the water-sediment interface is the key target for microbial studies, the ideal sample 
should include a fluid headspace that would demonstrate the interface has been captured.

Given the likely low-density, high-porosity sediment expected the eventual core could well be semi-fluid. When capturing a semi-fluid sample, there is always a risk of losing all, or part, of the sample if the core retention mechanism is not watertight. Furthermore, semi-fluid sediment layers have a stratigraphy that is very easy to disturb, and can be destroyed simply through the act of sampling if the method applied causes agitation, turbulence, or introduces movements of the coring apparatus during operation(Blomqvist 1991).

The factors that need to be considered when sampling soft sediments are reviewed by Blomqvist (1991) and also by Last and Smol (2001) who both describe major bias factors such as loss of surficial sediments, redistribution, and resuspension, or loss of enclosed sediment, core shortening, compression, and repenetration.

While we expect from the acoustic characterization studies that the sediment will be soft and fine grained (Woodward 2010) until sampling is achieved the exact nature of the sediment remains unknown. Consequently a corer for this application must perform in a wide range of sediments. It must enclose the sample without disturbing the stratigraphy and it should provide a way to remove the core intact from the sampler on recovery.

\section{Sampling conditions and effect on design}

Additional design factors to consider in the case of a pristine subglacial lake environment like Lake Ellsworth are that the sampling target is under pressure $(\sim 350 \mathrm{bar})$; is cold $\left(-2^{\circ} \mathrm{C}\right)$; and all sampling equipment must have a low endogenous microbial loading to prevent forward contamination of the lake environment (Seigert 2012). The latter requirement necessitates a design and choice of materials that facilitate cleaning and sterilization procedures. The cleaning procedures used by the Lake Ellsworth consortium include washing with detergent, ultra sonication, biocide, $70 \%$ ethanol, and hydrogen peroxide vapor (Seigert 2012; Magiopoulos et al. 2016; Pearce et al. 2016).

Once a borehole had been successfully created through the glacier to the lake surface, a sterile airlock would cap the hole and a series of sterilization procedures initiated to lower any bacterial loading. All equipment to enter the lake needs to pass through the airlock. It is estimated that the depth of the shaft will be $3000-3250 \mathrm{~m}$ and that the top $10 \%$ of this will be air-filled. The instrumented probe that includes the mini-corer described in this work would be the second object to pass down the shaft after a UV sterilization source has been passed through the air-filled section (Keen and Brito 2014). The probe, which includes a video camera and light system for continuously monitoring the area below the probe, will then be lowered on a conducting tether. On entering the lake the probe will proceed through the water column until the sediment surface is sighted and then allowed to slowly approach the surface minimizing any forward pressure wave that may disturb the sediment surface. Once within range of the water-sediment interface, as assessed visually by the operator from the live video feed, the mini-corer will be deployed. The core barrel and core capturing mechanism will be slowly wound down a lead screw to take a sample that includes a fluid headspace. Laboratory tests of the completed apparatus driven by motors on the probe have shown that deployment of the sampler takes approximately $3.5 \mathrm{~min}$. This equates to an approach velocity of $1 \mathrm{~mm} \mathrm{~s}^{-1}$ relative to the sediment. Consequently the possibility of core compression from any forward traveling pressure wave, or turbulence around the structure as it advances toward the sediment will be negligible. With estimated sediment depths well in excess of the sampler length confidence is high that the corer can be fully inserted.

On recovery the corer, and its sample, must traverse the water-filled borehole, followed by a cold (approximately $-18^{\circ} \mathrm{C}$ ) air-filled section expected to be $\sim 270 \mathrm{~m}$ in length prior to reaching the surface (Mowlem 2011). Since the probe is not insulated, and does not include heating systems, it is expected the core will freeze during ascent back to the ice sheet surface. When water freezes, it occupies approximately 9\% more volume than in its fluid state (Hobbs 1974). This poses a problem for a watertight core retention mechanism and a mechanism was required to compensate this increase in volume.

The corer mechanism must also be compatible with other sampling equipment on the instrument (Mowlem 2016). Water samples taken in separate water sampling carousels on the probe will be analyzed for a range of analytes including trace metals. Consequently every component of the mini-corer must be constructed from materials compatible with trace metal analysis such as titanium, Teflon ${ }^{\circledR}$, polyether ether ketone (PEEK), and ethylene propylene diene monomer (EPDM) rubber.

\section{Requirements summary}

1. A design that enables easy disinfection and use of materials resistant to these processes.

2. Use of materials that are compatible with trace metal analysis (Fe in particular).

3. A system capable of preserving stratigraphic integrity during the capture of a poorly consolidated sample.

4. A core capture mechanism that seals to prevent the loss of material and pore-water fractions.

5. A drive mechanism capable of inserting the corer over a wide range of sediment shear strengths.

6. A means of compensating for the volumetric increase in the sample as it freezes.

7. A method for removing the corer and its payload on recovery, that will not distort or contaminate the sample.

\section{A brief review of coring technologies}

Most sediment core samplers have a simple operating principle in that they: drive a tube into the sediment; cleave the 
enclosed sediment as close as possible to the penetrating edge of the tube; and allow the recovery of the resulting sample for analysis (Blomqvist 1991).

Despite these similarities, Neale and Walker (1996) note that bespoke design or careful selection of existing corer design is required in response to site conditions and logistics.

A number of "standard" corer types however have developed over time and are grouped primarily on the differentiating characteristic of their operating mode. Gravity corers (Livingstone 1955; Hopkins 1964; Young et al. 1990; Blomqvist 1991; Jahnke and Knight 1997; Glew et al. 2001; Kristoffersen et al. 2006) that use a mass to drive the core tube into the sediment, drill-tipped corers (Dickens and Kai-Uwe Hinrichs 2003) capable of taking long-rock samples, percussion corers where a mass is repeatedly used to drive a core barrel further into the sediment(Glew et al. 2001), push corers which are typically pushed into the sediment by a vehicle or operator for exploratory sediment work, and piston corers (Livingstone 1955; Cushing and Wright 1965; Wright 1967; Glew et al. 2001; Feek et al. 2006; Abegg et al. 2008) where the extending core barrel, coupled with a static piston, encloses the sample.

Driving the core tube into the sediment can be achieved in many ways; using a mass to overcome the shear strength of the sediment, thereby penetrating it, as typically used in gravity corers (Livingstone 1955; Hopkins 1964; Young et al. 1990; Kristoffersen et al. 2006); percussion mechanisms; vibration mechanisms such as on vibracorers (Glew et al. 2001); or static weight from a seabed frame (a form of gravity coring) (Jahnke and Knight 1997; Lunne and Long 2006). The Mackereth sampler (Mackereth 1958) drives a core barrel using compressed air. Differential hydrostatic pressures between the atmosphere and the deep ocean have also been used to drive a motor that pile drives a gravity corer deeper into the sediment in a manner similar to a percussion corer (Hopkins 1964; Kristoffersen et al. 2006). In the case described in this article, the corer is driven into the sediment on a lead screw.

The use of a static (relative to substrate) piston past which the core barrel is pushed dramatically reduces distortion of the sample particularly for soft sediments in aquatic settings by hydrostatically holding the expanding internal volume of the core barrel under tension relative to the external environment. In the absence of a piston, there is a potential for the core to be unrepresentative of the sediment structure. Compression is one mechanism by which this can occur particularly in the case of high-porosity sediments if the sampler approaches the substrate at such as speed that a bow pressure wave compacts the sediment, expelling interstitial pore water and shortening the sequence. With a piston held stationary above the sediment, surface compression is not possible (Cumming et al. 1993). In the sampling scenario addressed in this article, the corer would be slowly lowered to just above the sediment surface, under guidance from a live video connection to the surface, prior to deployment the corer. Core shortening, other than compression, can result if the friction between the core and the walls of the corer relative to the shear strength of the sediment begins to dominate. When this happens, material is pushed away from the corer's opening leading to thinning of deeper strata as the friction increases (Glew et al. 2001; Leroy and Colman 2001). When the wall friction equals or exceeds the sediment shear strength, the sample acts as a plug deflecting all further material ahead of it.

If a piston is used (Livingstone 1955; Miller and Holladay 1958; Cushing and Wright 1965; Wright 1967; McCoy and Von Herzen 1971; Jahnke and Knight 1997; Glew et al. 2001; Feek et al. 2006; Lunne and Long 2006; Abegg et al. 2008; Gardner et al. 2009), the frictional forces are balanced by a slight negative pressure in the water column enclosed within the core barrel relative to the surrounding ambient water pressure. As the core barrel extends any tendency for material to be deflected away from the opening due to frictional forces at the wall is compensated by increasing the negative pressure, or tension, above it until either the sediment shear strength is overcome, the entrance is permanently blocked, or the sample ruptures and the pressure differential is compensated by material and fluids being drawn in from surrounding sediment.

Other methods for capturing undisturbed samples in soft sediment are available. Wright (1980) for instance reported minimal sample distortion using a gravity corer that takes a sample on its external surface by freezing it in place. The core sample forms on the outside of the tube as the freezing front advances. Such corers are cooled internally with a dry ice and butanol mixture and drop through the water column to penetrate the sediment. The authors (Wright 1980) note that the fine-scale structure of the sediment is well preserved in the sample to within a millimeter of the surface of the freezing tube and attribute this minimal zone of disturbance to a low coefficient of friction between the surface of the freezing tube and the sediment due to the formation of a thin ice layer prior to the tube penetrating the sediment. The sampler is then held in place for $20-40$ min before being rapidly recovered complete with the frozen coating of water and sediment. This technique proved an effective countermeasure to the disturbance of delicately laminated sediments by gas bubbles evolved during depressurization because the sample was solidly frozen prior to ascent through the water column. However, this technique requires short-water transit times both on deployment and recovery and consequently is not suited to deep-subglacial lakebed sampling where deployment and recovery times are lengthy and temperatures already subzero, nor is the technique specifically targeted at the preservation of an undisturbed water/sediment interface.

Methods for retaining near liquid and poorly consolidated sediments within a core barrel following sampling include flap/cup valves at either end of the core barrel (Lunne and Long 2006; Abegg et al. 2008). However, existing designs mean that the valve at the lower end of the corer is only closed after extraction from the sediment, which risks the loss 
of poorly consolidated samples. In other cases, a sphincter valve has been used for cores of larger diameter using a nylon fabric diaphragm that twists after sample capture (Gardner et al. 2009).

While ball valves have previously been used in corers, to the best of our knowledge these have only been applied to high-pressure cores where the sample must be maintained at in situ pressure to preserve the properties of interest, for example, when sampling for gas hydrates (e.g., Abegg et al. 2008; Dickens and Kai-Uwe Hinrichs 2003). In such instances, the ball valve is closed after extracting the core from the sediment and is used to seal and maintain the in situ pressure within a separate pressure resistant chamber sealed by the ball valve.

It is common, with soft sediment corers where there is interest in capturing an undisturbed sediment surface, to deploy them from a sea- or lakebed frame that stabilizes them in position during the sampling stroke to minimize sediment surface disruption (e.g., Jahnke and Knight 1997; Leroy and Colman 2001; Lunne and Long 2006; Neale and Walker 1996). The Mackereth corer (Mackereth 1958) for instance has an anchor drum that is driven into the surrounding sediment providing lateral stability to the corer during corer deployment. The multicorers described by Barnett et al. (Lunne and Long 2006) and also by Jahnke and Knight (1997) are mounted on even more substantial seabed frames. All these deployment techniques offer the advantage of a stable sampling platform from which to activate corers. In the present case, the mini-corer will be part of a weighty probe (Mowlem 2016) suspended by a conducting tether immediately above the sediment in an inherently low-energy environment (Woodward 2010; Seigert 2012) and relies on the probe's mass to provide the stability necessary to capture an undisturbed core.

\section{Description of design}

The solution offered to the various design constraints outlined above is a small bore piston corer incorporating a low profile ball valve at the penetrating end (refer Figs. 1-3). The ball valves low profile minimizes resistance during penetration while still ensuring an effective seal after closure (refer Fig. 5).

The corer is $390 \mathrm{~mm}$ in length and is capable of capturing a composite sample of water and sediment up to $220 \mathrm{~mm}$ long.

When open the ball valve forms the cutting edge of the core barrel and when closed becomes the core catcher. The refinements offered here are that the sample will be retained even when it is almost entirely fluid, and that the valve is closed prior to extraction of the corer from the sediment meaning that there is little chance of the sample being lost on extraction. The piston mechanism is designed so the piston can move to accommodate any volumetric change due to freezing and relieve pressure from evolved gases.

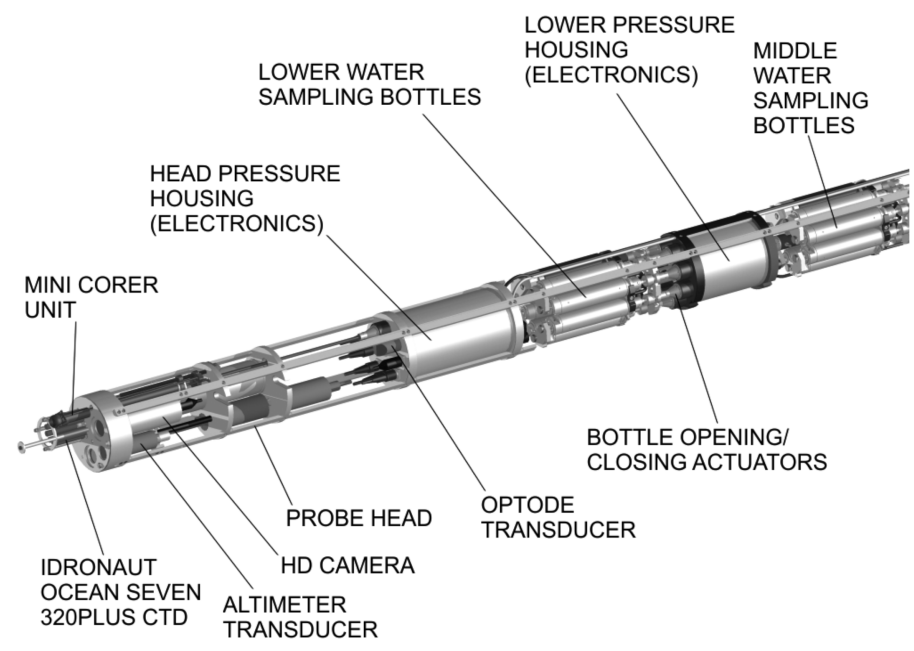

Fig. 1. Three-dimensional CAD model of the Lake Ellsworth probe illustrating the position of the corer in the tip of the structure.

All metallic parts of the corer are constructed from Titanium (grade $\mathrm{V}$ ) ensuring the validity of trace-Fe analysis for water samples also taken by the probe; nonmetallic components also comply with this requirement.

\section{Overview of operation}

A schematic of the corer and its drive mechanisms are shown in Figs. 3-4. A drive plate, driven by a lead screw, causes the extension of the core barrel past the piston and into the sediment. The lead screw itself is rotated by an electric motor, magnetically coupled to the drive assembly, via a drive shaft (refer Fig. 4). The lead screw also drives a ball drive plate that effects closure of the ball valve. A spur rod and stirrup assembly connects the ball drive plate to the ball valve (Figs. 2-3). The ball drive plate lags behind the drive plate by $37 \mathrm{~mm}$. The thread of the lead screw finishes before the end of the shaft allowing the drive plate to disengage from the lead screw at the end of its travel and permits the ball drive plate to continue being driven on its own. As a result the drive plate comes to rest against the back of the mounting head (refer Fig. 2) and the gap between the two plates closes forcing the spur rod to depress the stirrup and close the ball valve by rotating it through $90^{\circ}$. At this point, the sample is sealed within the corer barrel.

\section{Drive mechanism details}

Titanium has a tendency to bind (gall) when in frictional contact with itself (Miller and Holladay 1958). The threaded surfaces of the lead screw and the drive plates were therefore carbon coated in a plasma-assisted chemical vapor deposition process (DLC process-Tecvac, Buckingway Business Park, Swavesey, Cambridge, United Kingdom). This placed a diamondlike carbon coating $5 \mu \mathrm{m}$ thick, of great hardness and lubricity, on the contacting surfaces preventing them from binding under load. A polished rod on the opposite side of the core 


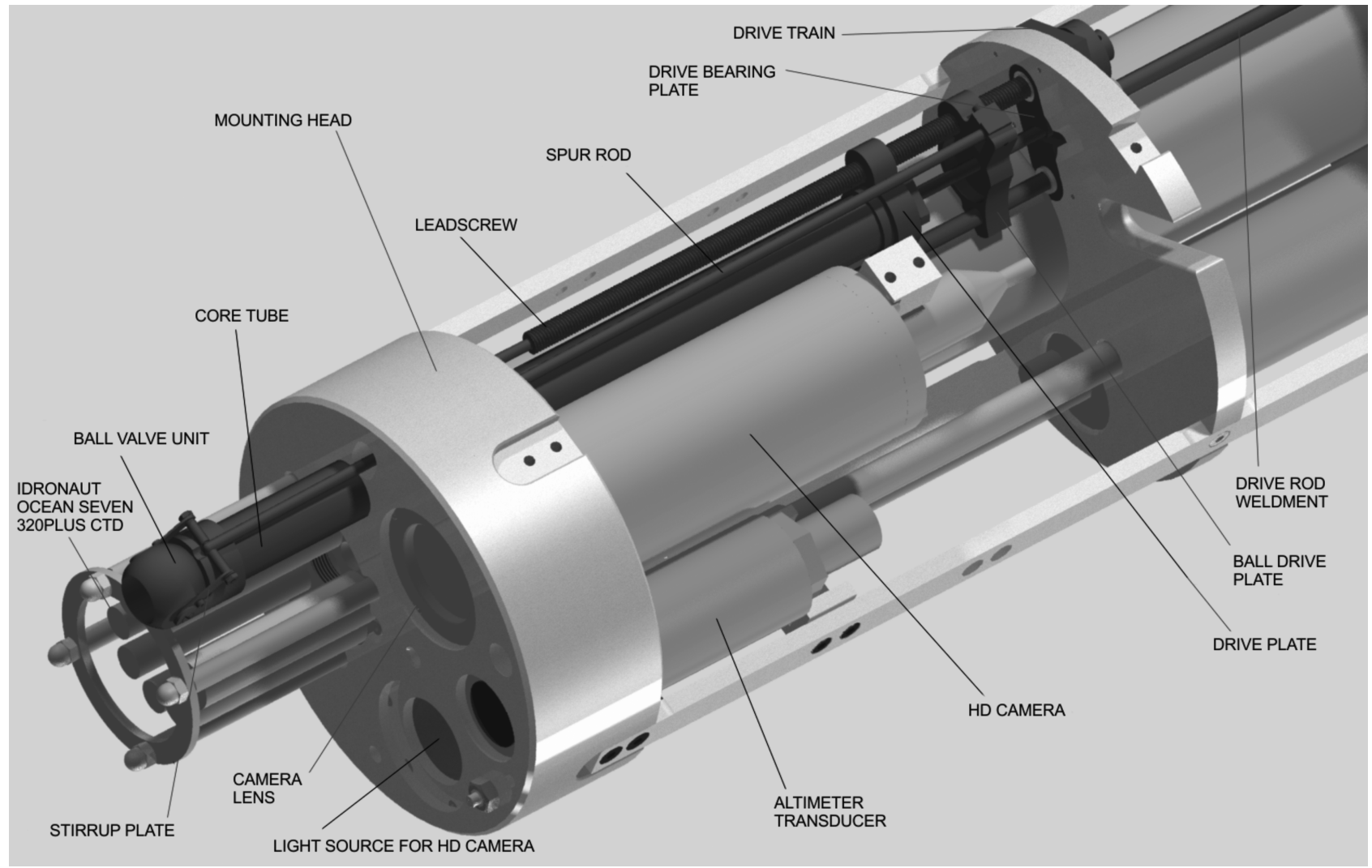

Fig. 2. A more detailed view of the probe head.

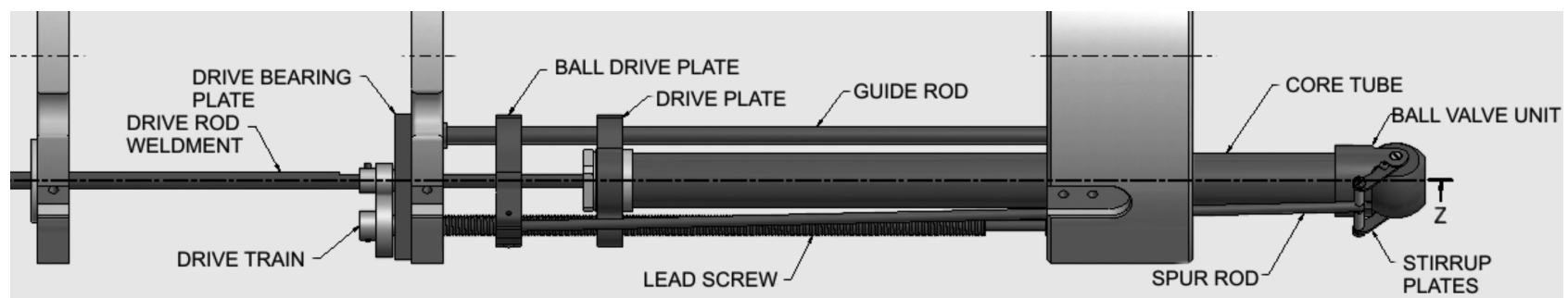

Fig. 3. Schematic of the corer and its drive mechanism.

barrel to the lead screw aligns this off-center drive arrangement. Guide holes in the drive plates for the guide rod were sleeved with Teflon ${ }^{\circledR}$ inserts to reduce friction and prevent the assembly from canting over and jamming.

The lead screw is aligned on a bearing at the mounting head end and an angular contact thrust bearing in the drive bearing plate. Both bearings are made of PEEK. The electric motor, acting through a magnetic coupling, rotates a drive shaft, pinion and spur gear combination with a $2: 1$ reduction ratio. The magnetic coupling provides a maximum torque of $1.75 \mathrm{Nm}$ before it yields so, in combination with the reduction gearing, $3.5 \mathrm{Nm}$ is available at the lead screw to drive the mechanism. The lead screw pitch further amplifies the mechanical advantage to the drive mechanism. The force was measured to be greater than $400 \mathrm{~N}$.
The drive plate and the ball drive plate are driven in tandem down the same lead screw maintaining a constant, $37 \mathrm{~mm}$, distance between them as they progress. This preserves the geometric relationship between the corer and the ball valve assembly during the sampling stroke that keeps the ball valve open.

At the forward end of the lead screw, an unthreaded section accommodates the drive plate once it has fully traversed the threaded section, at which point the drive plate disengages from the thread, is pushed up against the mounting head, and comes to rest. After disengagement, the lead screw drives the ball drive plate alone. The ball drive plate then approaches the drive plate pushing the spur rod forward relative to the ball valve causing it to rotate and close. The ball drive plate eventually meets the drive plate and at the same 


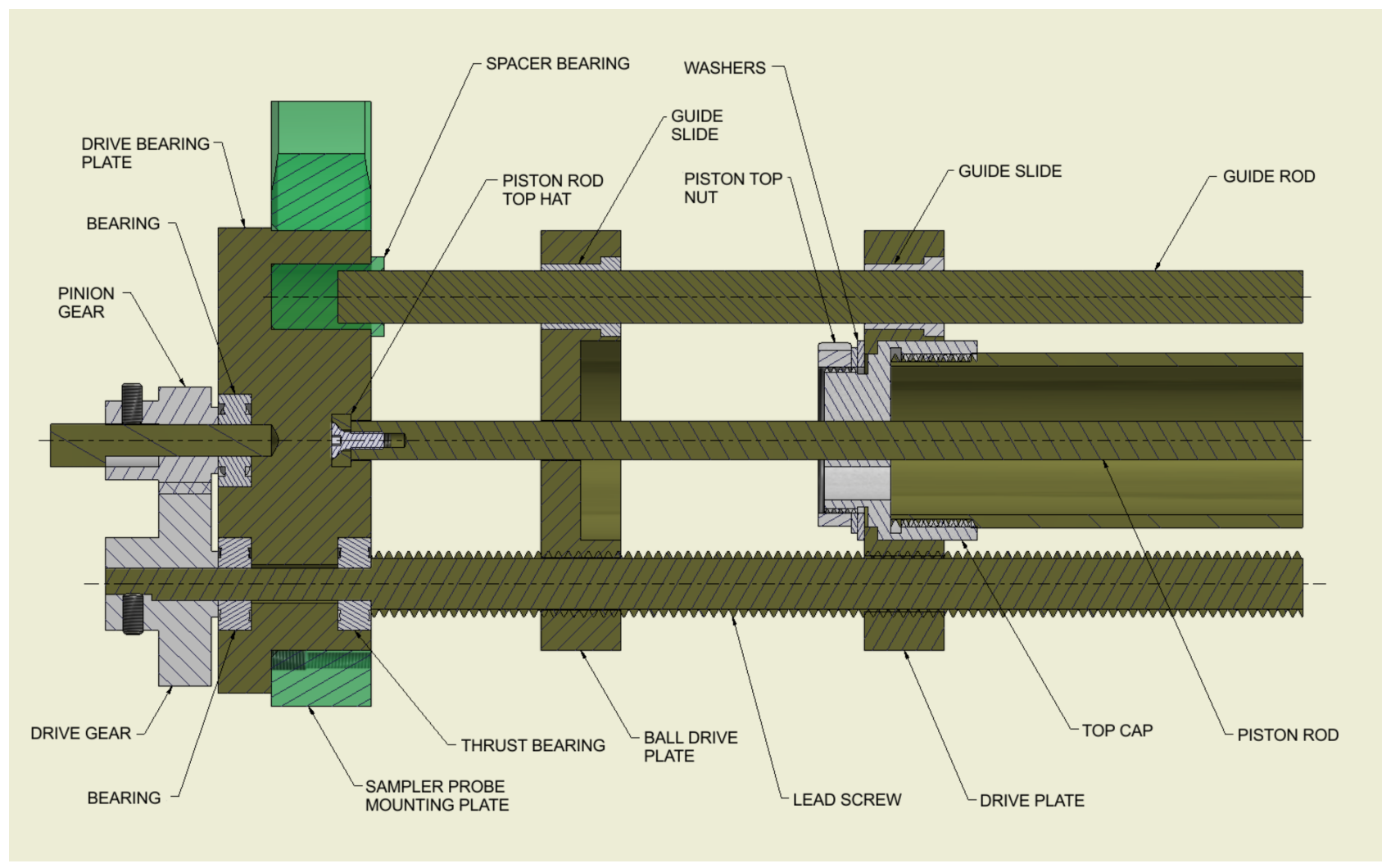

Fig. 4. Schematic of the corer drive mechanism.

time disengages from the threaded section of the lead screw, ceases its forward motion, and secures the closure to safeguard the sample.

The drive and ball closure mechanism is not designed to run in reverse once the drive plates have disengaged from the lead screw and there is no mechanism to reengage the threads on the drive plate remotely. This was not considered a significant drawback in the original design scenario because the probe is equipped with a live video feed to the surface. This allows an informed decision to be made by the operator about when to deploy the corer based on their observations.

\section{Details of piston construction and function}

The corer has a static piston (refer Fig. 5) held in place by a retainer at the end of a piston rod connected to the bearing plate (refer Fig. 4). The piston rod can be separated to allow removal of the core tube from the probe during sample recovery. The point of separation is above the top cap when the corer has been fully deployed.

The piston (refer Fig. 5) runs against the inner wall of the core tube with a low profile capped O-ring toward the front end and a wear ring toward the back end of the piston. These keep the piston aligned in the barrel and provide a seal against fluid intrusion past the piston from outside, thus allowing the hydraulic pressure compensation system to work.
The O-ring is formed from EPDM rubber and the cap is made from T99E polytetrafluoroethylene (PTFE) (10\% ekonol) that provides a relatively low coefficient of friction (0.27-0.29 +/-0.001; Qu et al. 2005) so the piston offers very little resistance to the movement of the core barrel past it but still forms an adequate seal.

The piston is constructed from PTFE and is formed in two parts. These screw together leaving a recess at the front end of the piston to accommodate the capped O-ring. This permits the O-ring cap to be fitted without having to stretch it over the front lip of the piston, which would permanently deform the cap and compromise the seal. The wear ring, also manufactured from T99E PTFE, was scarf cut to facilitate fitting in the rear recess and is not a sealing component.

The piston has an internal bore from its front end to a shoulder at the back. During deployment, the piston retainer is pulled to the back of the bore, seating against the shoulder. A small O-ring provides a seal between the piston retainer and the bore. Once the mechanism has gone through its full sampling action and the ball valve is closed, the piston acts as an upper seal to the core protecting it and preventing it from washing out during recovery to the surface.

Because the piston is only constrained by the piston retainer (see Fig. 5) against forward motion of the core barrel, it can compensate for volumetric changes (expansion) in the 


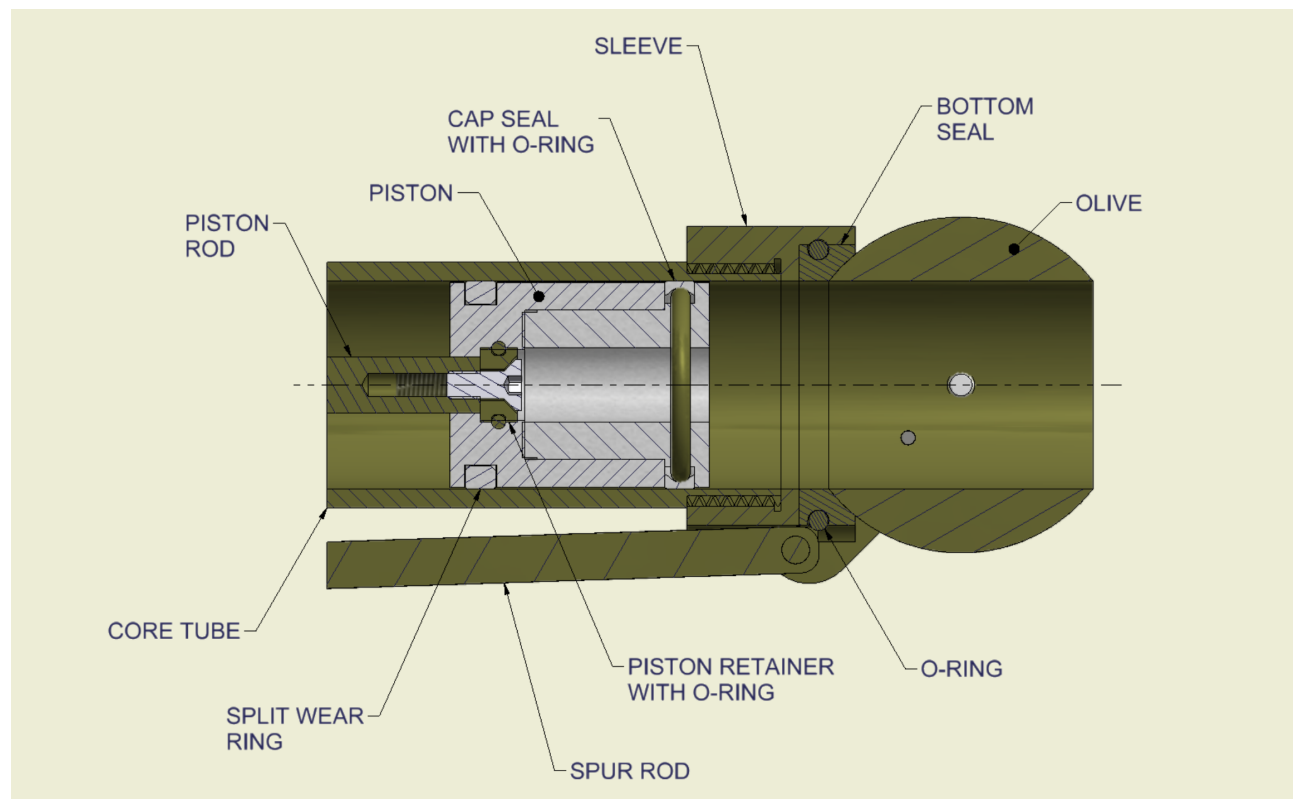

Fig. 5. Piston and ball drive schematic, shown partially retracted.

sample due to freezing because it can move backward in response to any internal pressure. After a linear displacement of $23 \mathrm{~mm}$ ( $7.8 \mathrm{~mL}$ or $9 \%$ of the sample volume), the piston retainer O-ring will clear the internal bore of the piston, breaking the gas seal and allowing the sample to vent if required.

\section{Details of ball valve construction and function}

The core closure mechanism is a modified inline ball valve referred to as the "Olive" (refer Fig. 5). The olive is housed in a separate sleeve assembly that threads on to the front end of the core barrel and forms the cutting edge of the corer. It was designed to be as small as possible to present a minimum cross section to the sediment while being sufficiently large to provide an effective seal when closed. The olive is penetrated by a bore that is the same internal diameter as the core barrel, and seats against a shaped PTFE seal housed in a recess between the olive and the sleeve (refer Fig. 5). The seat profile matches the curvature of the olive. An O-ring prevents the escape of any fluids around the outside of the seat forming a watertight seal underneath the sample once the valve has closed.

The olive is truncated under two cheek plates on either side to permit coupling with the spur rod via the stirrup that rotate the olive by $90^{\circ}$ and close it.

The corer can be removed from the main probe through partially disassembly. The Piston Rod can be separated above the Top Cap and the Spur Rod can be detached from the Ball Drive plate freeing the entire corer from the probe without disturbing the sample. The sample can then be transferred intact in its frozen state to a laboratory for extraction and analysis.

\section{Testing the completed apparatus}

Testing of function and performance was conducted in several stages. First, mechanical actuation and penetration were confirmed in sediment bucket samples under laboratory conditions.

Subsequently, two tests of the full probe assembly were conducted in the Empress Dock at the National Oceanography Centre, Southampton. The probe was lifted on its tether, lowered into the dock waters and held just above a sediment surface consisting of poorly consolidated, anoxic black silt and clay. The corer was deployed and a core obtained on two occasions. On recovery, the corer module was removed from the probe as described in the preceding section and the subassembly, including the enclosed sample, transferred to a freezer. Once frozen the core was extracted by running warm water over the outside of the core barrel, unscrewing the ball valve assembly, and sliding the core out as a frozen pellet using gentle downward pressure from the piston rod.

Sometime after these initial tests, the opportunity arose to conduct more comprehensive testing and a test jig was developed that enabled assessment of the corer's performance outside the context of the Ellsworth probe assembly. This allowed performance in a wider range of sediment types to be assessed. The jig consisted of a backing plate that supported analogues of the mounting head and the drive train mounting plate of the original assembly and maintained correct corer alignment which is critical for it to function correctly.

Sets of transparent acrylic core barrels and PEEK pistons were manufactured and a new sealing plug designed allowing us to take multiple samples for comparison, and assess ideas for different construction materials in the absence of the ironfree sampling constraint. 
The sealing plug has the same diameter as the internal diameter of the core barrel and the front face has a profile matching the curvature of the olive. This can then be inserted through the olive until it is flush with the outside surface forming a continuous curvature. The olive can then be rotated so the plug is in line with the core barrel and, with the assistance of an insertion tool, pushed up into the core barrel to seal it. The sample, being low in compressibility because of its water content, moves back as an intact plug and the piston, through its design, can move backward as well to accommodate the small displacement. An O-ring integrated into the plug assures a watertight seal and a cap can be screwed on the bottom of the core barrel to secure the plug in position.

The ball valve assembly can then be removed without exposing the lower part of the sample to the external environment at any time that would risk contamination or loss of material. The drive mechanism and ball valve assembly are now free to be reloaded with a new barrel and piston and take another sample and the current sample is safely contained within a simple, robust module for storage and transportation.

The corer in its new test jig, was assessed in a variety of environments, including the sandy littoral zone at Poole Harbour; in artificial sediment constructed from layers of colored sand (Colored Play Sands, Rainbow Eco Products, Radstock, United Kingdom), and was deployed in deep-marine sediments from an remotely operated vehicle (ROV) during the November 2016 RRS James Cook (JC142) expedition to the Tropic seamount in the North East Atlantic $\left(23^{\circ} 51.5^{\prime} \mathrm{N},-20^{\circ} 44.5^{\prime} \mathrm{W}, 1020 \mathrm{~m}\right.$ water depth).

Of interest during this testing program was the degree of disturbance; redistribution; compaction/compression; or distortion, of the sedimentary sequence by the apparatus during use. Push cores were collected alongside the mini-corer samples for comparison. The cores were stored frozen prior to examination and processed at the British Ocean Core Research Facility (BOSCORF) in Southampton.

These trials proved useful in developing techniques for handling these small cores, which were treated in a variety of ways to determine which method worked best. Intertidal cores were extruded as frozen pellets from the core barrel as previously described and transferred to half-round holders while still frozen. When sufficiently thawed, a cheese wire was used to cleave the core before imaging. Cores gathered on the JC142 expedition were frozen for storage and transportation but allowed to thaw in the laboratory. They were then drained partially of water while still in the core barrel following which the core barrel was split on a GeoTek manual core splitter. This was also the case for the artificially layered sand.

All cores were imaged on a GeoTek MSCL-CIS line scan camera (refer Figs. 6-8).

\section{Test results, discussion, and summary}

Coring under laboratory conditions confirmed that the drive mechanism on the probe could provide sufficient force to penetrate moderately consolidated estuarine mud. We were therefore confident that the mechanism has the ability to penetrate sediments likely to be found at the bottom of Lake Ellsworth.

In tests of the mini-corer following integration into the complete Lake Ellsworth probe conducted in the Empress Dock, we could demonstrate that the control systems in the probe could visualize the sediment surface, judge the distance and deploy the mini-corer into the sediment. The two cores that the dock tests produced were made up of a sediment section $160 \mathrm{~mm}$ in length and a fluid headspace of approximately $60 \mathrm{~mm}$. Closer inspection of these cores showed the water-sediment interface was preserved, and the pore-water fraction retained. Furthermore, the underlying sediment layers were intact and apparently undisturbed though there was nothing to directly compare this to for these samples and little variation within the sediment to differentiate layers in any event. The sediment surface appeared natural and the edges showed no indication of frictional drag at the barrel wall indicating that the hydraulic volume compensation provided by the piston worked as expected.

Subsequent test cores acquired with the test jig in the lab and in the field (refer Figs. 6-8 as examples) demonstrated that samples could be obtained with the mini-corer in all of the sediment types assessed, these ranged from compacted sand (Poole Harbour) to marine mud (Tropical Seamount). More importantly, push cores were taken in parallel to provide a comparison against which the mini-corer performance could be assessed. These inter-comparisons showed that distortion of the sediment surface in compacted sediments such as the sand flats in Poole Harbour was more evident in the push core samples, an example of which is shown in Fig. 6 where there is clear rolling off of the edges in the push core, while the mini-corer sediment surface edge is well delineated and more in keeping with what one would expect if a flat surface was intersected orthogonally by a cutting edge without distortion. This difference was much less apparent in the deep-sea mud samples taken on the Tropical Seamount and the artificially constructed sand layers from one of the laboratory trials.

The major difference between these sediment types is the degree of compaction, with the Poole Harbour sediment having the greatest of all types, and the sediment grain size, though the size of the intertidal sand from Poole and the artificial sand were of approximately the same order. From this, we would conclude that in highly compacted sediment the hydraulic pressure compensation by the piston is an advantage for preserving the structure of the sediment surface. In looser sediment types, this effect is less apparent. However, due to the way piston corers function, it would still confer an advantage in conserving a more representative record of deeper sediment layers by balancing increasing sediment friction over a growing inner wall surface area with a tensional force provided by the piston on the captive water column. 

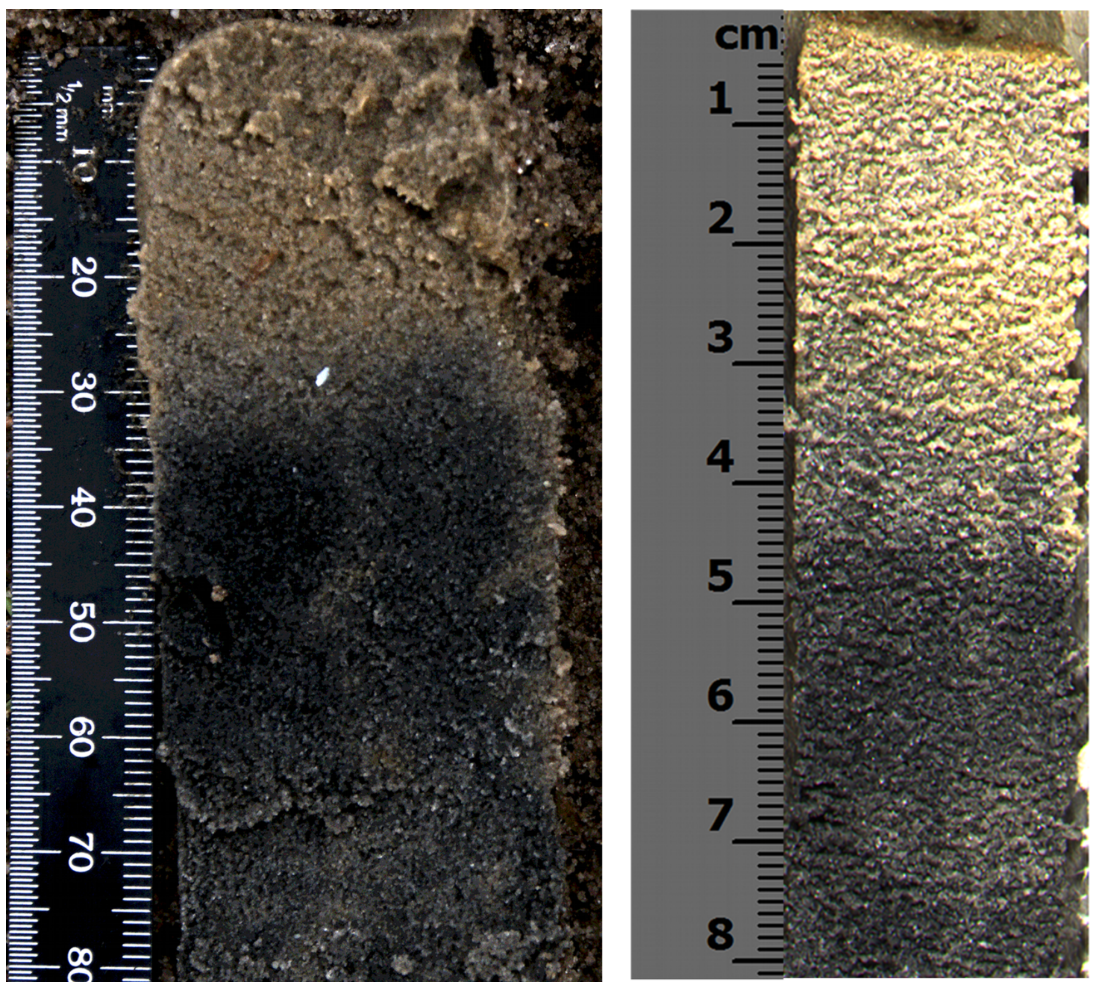

Fig. 6. Images of cores from Poole Harbour intertidal sand 18 January 2016; push core (Left), mini-corer (Right) illustrating the difference in depth of the anoxic layer and sediment surface preservation between the two techniques. The mini-corer retains the surface layer in its entirety whereas the push core suffers from washing out of the surface component during recovery (Geotek MSCL-CIS line scan camera, BOSCORF, UK).
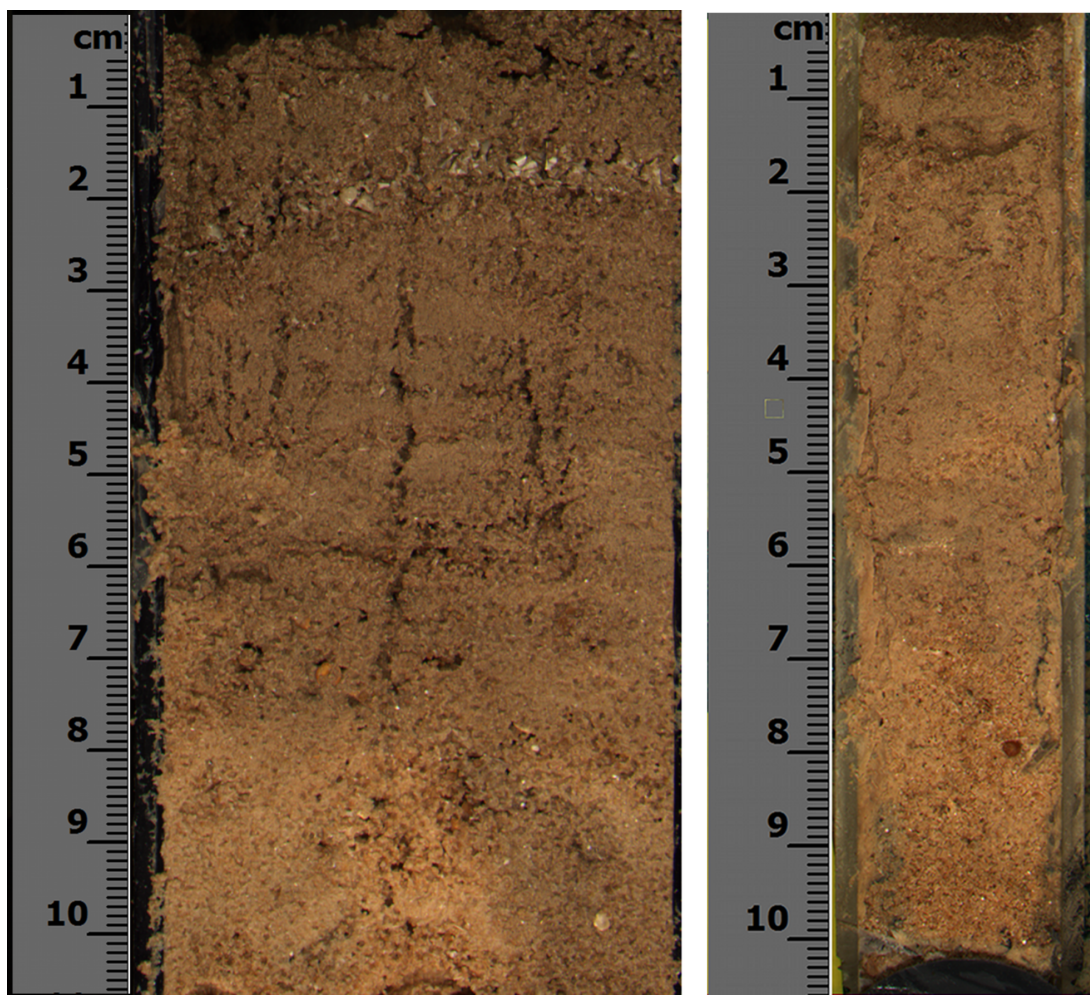

Fig. 7. Images of cores from tropic seamount sediment $\left(23^{\circ} 51.5^{\prime} \mathrm{N},-20^{\circ} 44.5^{\prime} \mathrm{W}, 1020 \mathrm{~m}\right)$; push core (Left), mini-corer (Right) demonstrating preservation of feature layer (foraminifera deposition) at $\sim 2 \mathrm{~cm}$ depth in both cores (Geotek MSCL-CIS line scan camera, BOSCORF, UK). 

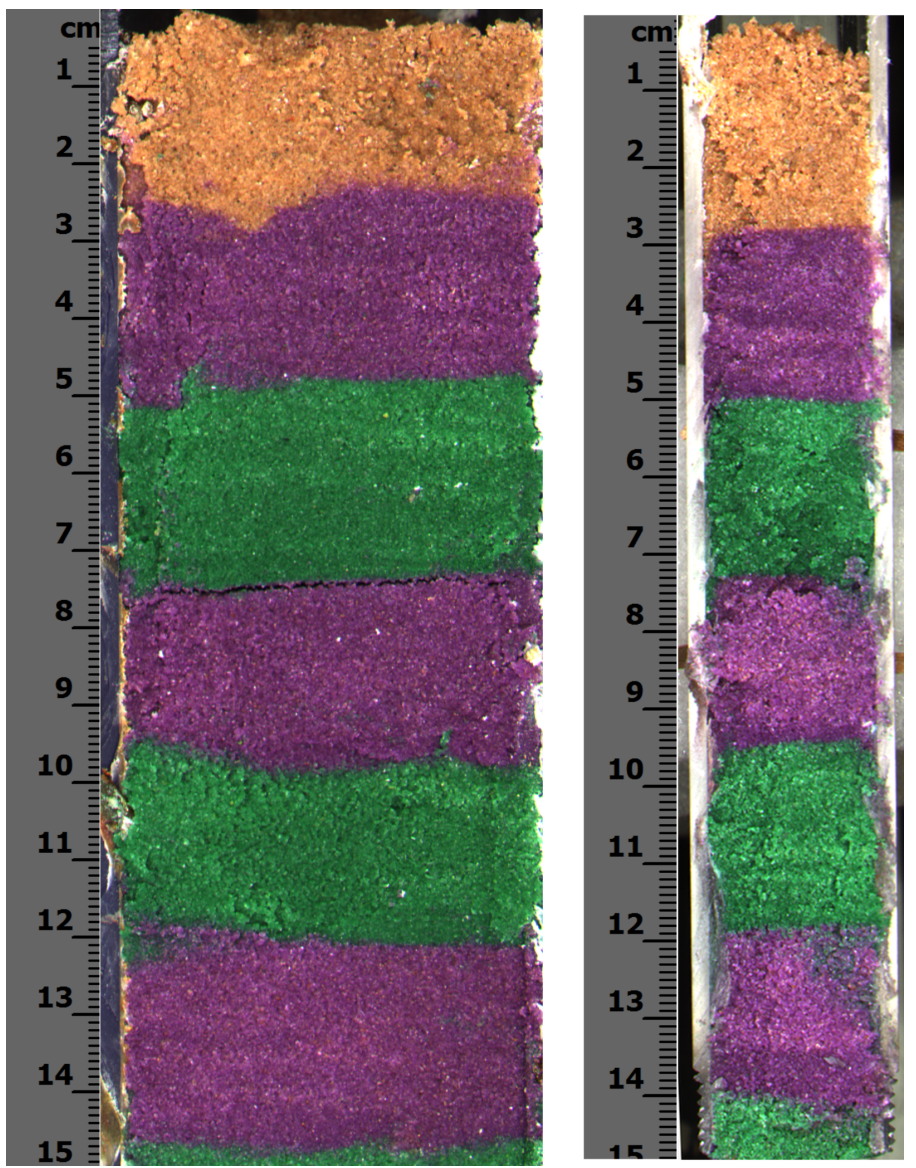

Fig. 8. Images of cores from artificially layered sand; push core (Left), mini-corer (Right). Hand compacted, commercially sourced, sand colored to display layers illustrating the conservation of layer sequence and thickness between the two techniques (Geotek MSCL-CIS line scan camera, BOSCORF, UK).

So this mini-corer can deliver short cores with intact watersediment interfaces of equal, or superior, quality compared to push cores taken from the same sediment type. The piston protects against thinning of deeper layers of the sediment.

The other major advantage of this design over push corers is that the mini-corer can retain the pore-water fraction in the samples and does not wash out on recovery. This is because the "olive" provides a watertight seal when it is closed, it closes prior to withdrawal from the sediment, and the piston bounds the sample at the top. This means there is no chance for material to fall out of the core barrel during its extraction from the sediment. Following recovery a plug can be inserted to protect the sample while it is being transported to an analysis facility. Plug insertion is achieved in an operation that does not expose the base of the core to contamination nor allows any fluids or solids to escape during the procedure.

The tests were basic and straightforward but the results are encouraging for the future development of this apparatus and its application to a wider range of underwater precision coring activities. Other improvements are currently under consideration with scaling the corer up in size being prime among them. What these tests do demonstrate is that the primary purpose of the design, to preserve a short, high-quality core with an intact and undisturbed water-sediment interface, can be met in a range of sediment types that extend beyond the low-density, high-porosity sediment type originally assumed for the design specification.

Subsequent "value engineering" work has shown that, when trace metal free sampling constraints are not imposed on construction materials, the apparatus can be made with lower cost materials, and the sample containment substructure can be modularized. This suggests the potential for lower cost per unit corer systems possibly in multicorer configurations enabling multiple samples of opportunity from any underwater platform capable of presenting the corer, in an appropriate way, to a substratum of interest.

The use of disposable plastic core barrels provides a core sample that can be split with a GeoTek manual core splitter, or the frozen core can be extruded as a solid pellet. Both techniques will conserve the water sediment junction if done with care though the frozen pellet method makes for more robust sample handling all other considerations being equal. Core barrels made of a transparent material make it easy to observe and image sediment strata through the wall of the liner prior to applying destructive methods of core sectioning and sampling.

The drive mechanism is compatible with a range of rotating drive types including magnetically coupled brushless DC motors, battery drills, and power take-off mechanisms (as found on some ROV's for instance). By fitting the apparatus into a simple frame, the mechanism can be adapted to fit a wider variety of deployment scenarios.

\section{Summary}

As part of a project to measure and sample the water and sediment of Subglacial Lake Ellsworth, a water and sediment sampling probe was designed and built. One of the requirements for this probe was a mechanism for sampling the water-sediment interface of the lakebed to answer questions regarding the existence of life in the lake. The small piston corer described in this article was designed and manufactured to address this requirement.

In order to fulfill the scientific objectives of acquiring a sample that would fulfill this requirement while not affecting other sampling systems on the probe the sampler had to conform to the following criteria:

1. The design must enable easy disinfection and use materials resistant to these processes.

2. Materials must be compatible with trace metal analysis (Fe in particular).

3. The system should be capable of preserving stratigraphic integrity during the capture of a low-density, high-porosity sample.

4. The core capture mechanism should prevent the loss of material and pore-water fractions. 
5. The drive mechanism must be capable of inserting the corer into sediment with a wide range of shear strengths.

6. A mechanism must be provided that compensates for a change in sample volume should the sample freeze or gas evolve.

7. There should be a simple method for removing the sample on recovery that does not disturb or contaminate the sample.

In response we have designed, built, and tested a corer constructed from materials that are resistant to the rigorous cleaning and disinfection processes required and which also comply with the requirement of iron (Fe) free trace metal analysis of water samples taken by the probe.

A ball valve core capturing mechanism coupled with a static piston was shown to cause minimal sediment surface disturbance, reduces the propensity for thinning of deeper sediment layers and prevents the loss of sediment and pore waters through an effective sealing mechanism.

The static piston was designed to compensate for volumetric changes in the sample, and we demonstrated that the sealed core barrel is not damaged by the sample freezing in the sample chamber.

Consideration was given to sample containment and transportation and an insertion plug/cap arrangement was designed that can secure the sample without compromising the watertight seal or damaging the sample.

\section{References}

Abegg, F., H. J. Hohnberg, T. Pape, G. Bohrmann, and J. Freitag. 2008. Development and application of pressurecore-sampling systems for the investigation of gas- and gashydrate-bearing sediments. Deep-Sea Res. Part I Oceanogr. Res. Pap. 55: 1590-1599. doi:10.1016/j.dsr.2008.06.006

Blomqvist, S. 1991. Quantitative sampling of soft bottom sediments: Problems and solutions. Mar. Ecol. Prog. Ser. 72: 295-304. doi:10.3354/meps072295

Cumming, B. F., J. R. Glew, J. P. Smol, and R. B. Davis. 1993. Comment on "core compression and surficial sediment loss of lake sediments of high porosity caused by gravity coring" (Crusius and Anderson). Limnol. Oceanogr. 38: 695-699. doi:10.4319/1o.1993.38.3.0695

Cushing, E. J., and H. E. Wright. 1965. Hand operated piston corers for lake sediments. Ecology 46: 380-384. doi: $10.2307 / 1936353$

Gerald R. Dickens, D.S. Kai-Uwe Hinrichs. 2003. The pressure core sampler (PCS) on ODP Leg 201: General operations and gas release, p. 1-22. In Proceedings of the Ocean Drilling Program, Initial Reports, v. 201.

Dickens, G.R., D. Schroeder, K.-U. Hinrichs, and the Leg 201 Scientific Party, 2003. The pressure core sampler (PCS) on Ocean Drilling Program Leg 201: general operations and gas release. In D'Hondt, S.L., Jørgensen, B.B., Miller, D.J., et al, Proc. ODP, Init. Rept. 201: College Station, TX
(Ocean Drilling Program), 1-22. doi:10.2973/odp.proc. ir.201.103.2003

Feek, D. T., J. R. Flenley, P. I. Chester, N. Welikala, E. A. Matisoo-Smith, and G. W. Tannock. 2006. A modified sampler for uncontaminated DNA cores from soft sediments. J. Archaeol. Sci. 33: 573-574. doi:10.1016/j.jas.2005.09.013 Gardner, W. S., M. J. McCarthy, S. A. Carini, A. C. Souza, H. Lijun, K. S. McNeal, M. K. Puckett, and J. Pennington. 2009. Collection of intact sediment cores with overlying water to study nitrogen- and oxygen-dynamics in regions with seasonal hypoxia. Cont. Shelf Res. 29: 2207-2213. doi:10.1016/j.csr.2009.08.012

Glew, J. R., J. P. Smol, and W. M. Last. 2001. Sediment core collection and extrusion. In W. M. Last and J. P. Smol [eds.] Tracking environmental change using lake sediments: Basin analysis, coring, and chronological techniques, p. 73-105. Springer.

Hobbs, P. V. 1974. Ice physics. Clarendon Press.

Hodgson, D. A. and others 2016. Technologies for retrieving sediment cores in Antarctic subglacial settings. Philos. Trans. R. Soc. Lond. A Math. Phys. Eng. Sci. 374: 20150056.

Hopkins, T. L. 1964. A survey of marine bottom samplers. Prog. Oceanogr. 2: 213-256. doi:10.1016/0079-6611(64)90005-9

Jahnke, R. A., and L. H. Knight. 1997. A gravity-driven, hydraulically-damped multiple piston corer for sampling fine-grained sediments. Deep-Sea Res. Part I Oceanogr. Res. Pap. 44: 713-718.

Keen, P. W., and M. P. Brito. 2014. Design considerations and solutions in rapid-prototyping an ultraviolet reactor for ice borehole disinfection. Ann. Glaciol. 55: 74-82. doi: 10.3189/2014AoG65A006

Kennicutt, M. C. and others 2014. A roadmap for Antarctic and southern ocean science for the next two decades and beyond. Antarct. Sci. 27: 3-18.

Kristoffersen, Y., E. Lien, K. Festervoll, S. Ree, K. Åardahl, and $\varnothing$. Hosøy. 2006. The hydrostatic corer Selcore-a tool for sediment sampling and geophysical site characterization. Mar. Geol. 229: 101-112. doi:10.1016/j.margeo.2006.02.007

Last, W. M., and J. P. Smol. 2001. Tracking environmental change using lake sediments. Springer.

Leroy, S. A. G., and S. M. Colman. 2001. Coring and drilling equipment and procedures for recovery of long lacustrine sequences. In W. M. Last and J. P. Smol [eds.] Tracking environmental change using lake sediments: Basin analysis, coring, and chronological techniques, p. 107-135. Springer.

Livingstone, D. A. 1955. A lightweight piston sampler for lake deposits. Ecology 36: 137-139. doi:10.2307/1931439

Lunne, T., and M. Long. 2006. Review of long seabed samplers and criteria for new sampler design. Mar. Geol. 226: 145-165. doi:10.1016/j.margeo.2005.07.014

Mackereth, F. J. H. 1958. A portable core sampler for lake deposits. Limnol. Oceanogr. 3: 181-191. doi:10.4319/lo.1958.3.2.0181

Magiopoulos, I., J. S. McQuillan, C. L. Burd, M. Mowlem, and M. N. Tsaloglou. 2016. A multi-parametric assessment of 
decontamination protocols for the subglacial Lake Ellsworth probe. J. Microbiol. Methods 123: 87-93. doi: 10.1016/j.mimet.2016.02.012

McCoy, F. W., and R. P. Von Herzen. 1971. Deep-sea corehead camera photography and piston coring. Deep-Sea Res. Oceanogr. Abstr. 18: 361-373. doi:10.1016/0011-7471(71) 90041-6

Miller, P. D., and J. W. Holladay. 1958. Friction and wear properties of titanium. Wear 2: 133-140. doi:10.1016/0043-1648 (58)90428-9

Mowlem, M. and others 2016. Probe technologies for clean sampling and measurement of subglacial lakes. Philos. Trans. R. Soc. Math. Phys. Eng. Sci. 374: 20150267.

Mowlem, M. C. and others 2011. Probe Technology for the Direct Measurement and Sampling of Ellsworth Subglacial Lake, In M. J. Siegert [ed.], Antartic subglacial aquatic environments. American Geophysical Union, p. 159-186. doi: 10.1029/2010GM001013

Neale, J. L., and D. Walker. 1996. Sampling sediment under warm deep water. Quat. Sci. Rev. 15: 581-590. doi: 10.1016/0277-3791(96)00010-8

Pearce, D. A., I. Magiopoulos, M. Mowlem, M. Tranter, G. Holt, J. Woodward, and M. J. Siegert. 2016. Microbiology: Lessons from a first attempt at Lake Ellsworth. Philos. Trans. R. Soc. Math. Phys. Eng. Sci. 374: 20140291.

Qu, J., P. J. Blau, T. Watkins, O. Cavin, and N. Kulkarni. 2005. Friction and wear of titanium alloys sliding against metal, polymer, and ceramic counterfaces. Wear 258: 1348-1356. doi:10.1016/j.wear.2004.09.062

Seigert, M. J. and others 2012. Clean access, measurement, and sampling of Ellsworth Subglacial Lake: A method for exploring deep Antarctic subglacial lake environments. Rev. Geophys. 50: RG1003.

Siegert, M. J. 2016. Research focus: A wide variety of unique environments beneath the Antarctic ice sheet. Geology 44: 399-400. doi:10.1130/focus052016.1

Siegert, M. J., R. Hindmarsh, H. Corr, A. Smith, J. Woodward, E. C. King, A. J. Payne, and I. Joughin. 2004. Subglacial Lake Ellsworth: A candidate for in situ exploration in West Antarctica. Geophys. Res. Lett. 31: 1-4. doi: 10.1029/2004GL021477

Siegert, M. J. and others 2006. Exploration of Ellsworth Subglacial Lake: A concept paper on the development, organisation and execution of an experiment to explore, measure and sample the environment of a West Antarctic subglacial lake. Rev. Environ. Sci. Biotechnol. 6: 161-179.

Siegert, M. J., K. Makinson, D. Blake, M. Mowlem, and N. Ross. 2014. An assessment of deep hot-water drilling as a means to undertake direct measurement and sampling of Antarctic subglacial lakes: Experience and lessons learned from the Lake Ellsworth field season 2012/13. Ann. Glaciol. 55: 59-73. doi:10.3189/2014AoG65A008

Siegert, M. J., J. C. Priscu, I. A. Alekhina, J. L. Wadham, and W. B. Lyons. 2015. Antarctic subglacial lake exploration: First results and future plans. Philos. Trans. R. Soc. A Math. Phys. Eng. Sci. 374: 1-12.

Smith, A. M. and others 2008. Physical conditions in subglacial Lake Ellsworth. EOS Trans. 89.

Vaughan, D. G., A. Rivera, J. Woodward, H. F. J. Corr, J. Wendt, and R. Zamora. 2007. Topographic and hydrological controls on subglacial Lake Ellsworth, West Antarctica. Geophys. Res. Lett. 34: L18501. doi:10.1029/2007GL030769

Woodward, J. and others 2010. Location for direct access to subglacial Lake Ellsworth: An assessment of geophysical data and modeling. Geophys. Res. Lett. 37: 1-5 doi: 10.1029/2010GL042884

Wright, H. E. 1967. A square-rod piston sampler for lake sediments. J. Sediment. Res. 37: 975-976. doi:10.1306/ 74D71807-2B21-11D7-8648000102C1865D

Wright, H. E. 1980. Cores of soft lake sediments. Boreas 9: 107-114.

Young, I. M., G. Wilson, J. Wallace, and C. E. Mullins. 1990. A mini-corer for relative soil strength studies. J. Agric. Eng. Res. 46: 77-79. doi:10.1016/S0021-8634(05)80115-5

\section{Acknowledgments}

The authors extend their thanks and gratitude to Thanos GkritzalisPapadopoulos for project management and liason during the first stage of the project. To the British Ocean Sediment Core Research Facility (BOSCORF), in particular, we would like to thank Guy Rothwell and Suzanne MacLachlan as well as Lewis Bailey for making available BOSCORF facilities and assisting with the examination of the test cores. Our thanks are also due to Bramley Murton, PI on the JC142 expedition for making time in his programme to allow us to test the corer at depth on the ISIS ROV as well as to the ROV team on board at the time. Finally we would like to extend our thanks to Dominic Hodgson of the British Antarctic Survey for reviewing and commenting on drafts of this paper. This research was supported by UK Natural Environment Research Council Consortium Grant (NE/G006326/1) and subcontract NE/G004242/1.

\section{Conflict of Interest}

None declared.
Submitted 1 May 2018

Accepted 19 September 2018

Associate editor: George Waldbusser 